\title{
Sobre el concepto jurídico de persona con discapacidad y la noción de apoyos necesarios
}

\author{
Review of the juridical concept of person \\ with disability and the notion of necessary \\ supports
}

\section{Resumen}

En el presente artículo se realiza una revisión del concepto jurídico de persona con discapacidad que es utilizado por la Ley General de Discapacidad de 2013, en consonancia con la Convención de Naciones Unidas sobre los derechos de las personas con discapacidad, y en la jurisprudencia del Tribunal de Justicia de la Unión Europea. Se concibe como un concepto jurídico indeterminado que tiene su núcleo de certeza en la inexistencia de apoyos necesarios o ayudas para superar las barreras sociales que sufren las personas con deficiencias (físicas, mentales, intelectuales o sensoriales) previsiblemente permanentes. De ahí que la noción de apoyos necesarios deba tener una mayor relevancia en el concepto de persona con discapacidad y se estudien las consecuencias prácticas de esta tesis. Por último, se reflexiona tanto sobre la necesidad o no de tener una declaración administrativa para tener la consideración de persona con discapacidad como sobre la equiparación en todo caso entre esta noción y la de persona con incapacidad permanente de la Seguridad Social.

\section{Palabras clave}

Discapacidad, apoyos necesarios, declaración administrativa, incapacidad permanente.

\begin{abstract}
This article presents a review of the juridical concept of person's with disability that is used by the General Law of Disability of 2013, in agreement with the United Nations Convention on the Rights of Persons with Disabilities, and with the jurisprudence of the Court of Justice of the European Union. It is conceived as a juridical indeterminate concept that has its core of certainty in the nonexistence of necessary supports or assistance to overcome the social barriers experienced by persons with predictably permanent deficiencies (physical, mental, intellectual or sensory). Hence the notion of necessary supports should have a greater relevance in the juridical concept of person with disability and there are studied the practical consequences of this thesis. Finally, we reflect upon the need of having an administrative declaration to have the consideration of person with disability as of the comparison in any case between this notion and the notion of person with permanent invalidity of the National Health Service.

\section{Keywords}

\section{Carlos de Fuentes García- Romero de Tejada \\ <carlosdefuentes@yahoo.es>}

Fundación Manantial. Universidad Complutense de Madrid.

Para citar:

De Fuentes, C. (20I6): "Sobre el concepto jurídico de persona con discapacidad y la noción de apoyos necesarios". Revista Española de Discapacidad, 4 (2): 8 I-99.
\end{abstract}

Disability, necessary supports, administrative declaration, permanent invalidity.
Doi: <https://doi.org/IO. 5569/23405 I04.04.02.05>

Fecha de recepción: OI-O2-20I6 Fecha de aceptación: 03-I0-20I6 


\section{Introducción}

La discapacidad es una realidad social, y por ende jurídica, que cuenta ya con una sólida tradición científica. Prescindiendo de la historia del concepto de discapacidad y su diferenciación con otras figuras como minusvalía al entender ya superada esta fase que ha sido estudiada por otros autores (García, 2005: 27; Tuset, 2000 y 20II: 47; Esteban, I999: 35), seguimos a De Lorenzo y Pérez Bueno (2007) en el Tratado sobre Discapacidad para entender este concepto como una diferencia específica de las personas a las que afecta, que genera una situación de desigualdad social objetiva de partida que conlleva la necesidad de establecer medidas de apoyo y de acción positiva para alcanzar la igualdad de oportunidades real (De Asís et al., 2007: I 16). Aunque ya está derogada por el Real Decreto-Legislativo I/20I3, de 29 de noviembre, por el que se aprueba el Texto Refundido de la Ley General de derechos de las personas con discapacidad y de su inclusión social (en adelante, LGD), recogemos las palabras de la Exposición de Motivos de la Ley 51/2003, de Igualdad de Oportunidades, No Discriminación y Accesibilidad Universal de las personas con discapacidad, conocida comúnmente por su acrónimo LIONDAU: "Las personas con discapacidad constituyen un sector de población heterogéneo, pero todas tienen en común que, en mayor o menor medida, precisan de garantías suplementarias para vivir con plenitud de derechos o para participar en igualdad de condiciones que el resto de ciudadanos en la vida económica, social y cultural del país”.

Esta diferencia, que según la letra e) del Preámbulo de la Convención de Naciones Unidas sobre los Derechos de las Personas con Discapacidad de I 3 de diciembre de 2006 ratificada por España en 2008 (en adelante, la Convención), evoluciona con el tiempo, tiene su origen en la imposibilidad de la sociedad de ser inclusiva para todas las diversidades humanas. Esto es, la sociedad encierra un entorno inadecuado para el colectivo de personas que presentan una deficiencia de algún tipo porque está diseñada en el parámetro de "persona media” (De Asís et al., 2007: I I6) o "persona normal” (Pérez Bueno y De Lorenzo, 2007: I 155 ). De la interacción entre esta sociedad y las personas con algún tipo de deficiencia (física, mental, intelectual o sensorial) que viven en ella surgen barreras que pueden impedir o, cuanto menos, dificultar la participación plena y efectiva en la sociedad, en igualdad de condiciones con los demás.

Seguimos, pues, el llamado "modelo social" que considera a la discapacidad "como un fenómeno cuyo origen se debe en gran medida a causas sociales, que no es simplemente un atributo de la persona, sino un complejo conjunto de condiciones, muchas de las cuales son creadas por el contexto social. En consecuencia, el manejo del tema requiere la realización de todas las modificaciones y adaptaciones ambientales necesarias, a fines de alcanzar la participación plena de las personas con discapacidad en la totalidad de las áreas de la vida en comunidad" (De Asís et al., 2007: 90). En otras palabras, tal como indica Jiménez Lara (2007) “se ha abierto paso el convencimiento de que, si modificamos la forma en que organizamos nuestras sociedades, podremos reducir considerablemente e incluso eliminar las dificultades y barreras a las que se enfrentan las personas con discapacidad y muchos otros grupos para llevar una vida independiente y plena”.

En definitiva, se asume un enfoque de derechos humanos y social cuyo objetivo, como ha dicho de manera inmejorable García Garnica (20II), "no será la normalización de la persona con discapacidad, sino la normalización de la sociedad, para hacer frente a las necesidades de todas las personas".

\section{La definición legal de discapacidad}

La LGD ha llevado a cabo por primera vez una definición del concepto de discapacidad acogiendo el modelo social de la misma y 
superando el referente médico de las normas precedentes. Esta Ley cuyo objeto es la regularización, aclaración y armonización de tres leyes emblemáticas en el ámbito de la discapacidad como son la LISMI (Ley I3/I982, de 7 de abril de integración social de las personas con discapacidad), la LIONDAU antes citada y la Ley 49/2007, de 26 de diciembre, de infracciones y sanciones en materia de igualdad de oportunidades, no discriminación y accesibilidad universal de las personas con discapacidad, "es más que una simple compilación de normas jurídicas” (Cabra de Luna, 20I4: I) y un exponente de ello es que por primera vez realiza una verdadera elaboración definitoria del término discapacidad, cuestión reivindicada desde hace años por el movimiento asociativo de la discapacidad (De Lorenzo y Cabra de Luna, 2007: I I 53 y Pérez Bueno y De Lorenzo, 2007: I 560).

Tal elaboración conceptual realizada en el artículo 2.a) de la LGD trae su causa de la definición de persona con discapacidad del artículo I de la Convención de la ONU, que literalmente reza:

\footnotetext{
"Las personas con discapacidad incluyen a aquellas que tengan deficiencias físicas, mentales, intelectuales o sensoriales a largo plazo que, al interactuar con diversas barreras, puedan impedir su participación plena y efectiva en la sociedad, en igualdad de condiciones con las demás”.
}

Partiendo de esta noción elaborada por Naciones Unidas, nuestra LGD establece que discapacidad "es una situación que resulta de la interacción entre las personas con deficiencias previsiblemente permanentes y cualquier tipo de barreras que limiten o impidan su participación plena y efectiva en la sociedad, en igualdad de condiciones con las demás”.

\section{La discapacidad, concepto jurídico indeterminado}

De la lectura de la definición recién apuntada puede desprenderse con facilidad la existencia de varios términos indeterminados. En primer lugar, "las personas con deficiencias previsiblemente permanentes" que para saber quiénes son nos tenemos que ir a los artículos 4.I y 2 de la propia $\mathrm{LGD}^{\mathrm{I}}$; en segundo, “cualquier tipo de barreras que limitan o impidan" $y$, en tercer término, la "participación plena y efectiva en la sociedad, en igualdad de condiciones con las demás”. Con estas notas, propias de todo concepto jurídico indeterminado, se consigue un molde flexible y dinámico (Esteban, I999: 45) que permite sin necesidad de listar las deficiencias, ni las barreras, ni el grado de participación efectiva en la sociedad, establecer un concepto "para lograr así una solución justa" (Álvarez, I982: I83) en cada caso o para un conjunto de personas en situación semejante.

Como ya se conoce por la labor de la mejor doctrina jurídica administrativista (García de Enterría) todo concepto jurídico indeterminado tiene "un núcleo cierto o zona de certeza positiva" a partir del cual se puede conocer o tener evidencia de qué está incluido en él y qué puede entenderse que no cae dentro de dicho concepto jurídico indeterminado (Álvarez, I982: I82-I89).

\footnotetext{
I. Artículo 4. Titulares de los derechos.

I. Son personas con discapacidad aquellas que presentan deficiencias físicas, mentales, intelectuales o sensoriales, previsiblemente permanentes que, al interactuar con diversas barreras, pueden impedir su participación plena y efectiva en la sociedad, en igualdad de condiciones con los demás. 2. Además de lo establecido en el párrafo anterior, y a todos los efectos, tendrán la consideración de personas con discapacidad aquellas a quienes se les haya reconocido un grado de discapacidad igual o superior al 33 por ciento. Se considerará que presentan una discapacidad en grado igual o superior al 33 por ciento los pensionistas de la Seguridad Social que tengan reconocida una pensión de incapacidad en el grado de total, absoluta o gran invalidez, y a los pensionistas de clases pasivas que tengan reconocida una pensión de jubilación o de retiro por incapacidad permanente para el servicio o inutilidad.

3. Las normas que regulen los beneficios o medidas de acción positiva podrán determinar los requisitos específicos para acceder a los mismos.
} 


\section{La esencia de la discapacidad, las barreras sociales y la falta de medidas de apoyo para superar las limitaciones que éstas provocan}

Para lograr identificar la esencia del concepto de discapacidad se debe partir del hecho de que el legislador, en consonancia con la Convención de Naciones Unidas, ha establecido una definición de esta institución que tiene categoría propia y va más allá de la suma de los requisitos antedichos. Esto es, la discapacidad no es la deficiencia, ni tampoco es la barrera que dificulta que las personas con deficiencias puedan participar plena y efectivamente en la sociedad sino que es "la interacción" entre ambas (las personas con deficiencias y las barreras). La LGD trata pues de poner el foco de atención no sólo en la barrera social sino en que cuando ésta exista no pueda ser sorteada y, por ello, impide la plena participación de las personas con discapacidad.

Por tanto, la discapacidad debe entenderse con rigor y técnicamente, en primer lugar y de manera principal, como el resultado de la incapacidad de la sociedad para impedir que haya barreras u obstáculos a la participación efectiva de las personas que presentan alguna deficiencia permanente. Y, en segundo término, de un modo más práctico, también debe concebirse como la imposibilidad de la sociedad de articular medidas para poder sortear las barreras existentes o, en otras palabras, la inexistencia de medidas de apoyo suficientes y ordinarias para superar dichos obstáculos. Habría pues dos planos teóricos para conceptualizar la discapacidad: un plano del "deber ser" en el cual la sociedad debe ser sencillamente "sin barreras o accesible", gracias fundamentalmente al "diseño universal o diseño para todas las personas” ${ }^{2}$, y otro plano más

2. Definido en la letra 1) del artículo 2 de la LGD como "la actividad por la que se conciben o proyectan desde el origen, y siempre que sea posible, entornos, procesos, bienes, productos, servicios, objetos, instrumentos, programas, dispositivos o herramientas, de tal forma que puedan ser utilizados por todas las personas, en la mayor extensión posible, sin necesidad de adaptación ni diseño especializado”, aunque -sigue diciendo práctico o del "ser" en el cual, reconociendo que en relación a las personas con deficiencias permanentes en la sociedad se dan barreras y obstáculos a su participación, se deben articular medidas de apoyo para poder superarlas.

Si bien se mira entonces, el nudo gordiano del concepto de discapacidad no es la existencia de una persona con alguna deficiencia de carácter permanente de tipo físico, mental, intelectual o sensorial; ni siquiera que estas personas tengan barreras que les impidan participar en la sociedad en igualdad de condiciones con las demás, sino que no tengan medidas de apoyo efectivas que les permitan superar o paliar las barreras existentes.

En efecto, tal y como nos dijeron de manera magistral De Lorenzo y Palacios (2007: 7) "se considera que una incapacidad para caminar es una deficiencia, mientras que una incapacidad para entrar a un edificio debido a que la entrada consiste exclusivamente en una escalera es una discapacidad. Una incapacidad para hablar es una deficiencia, pero la incapacidad para comunicarse, porque las ayudas técnicas no se encuentran disponibles, es una discapacidad. Una incapacidad para moverse es una deficiencia, pero la incapacidad para salir de la cama debido a la falta de disponibilidad de ayuda apropiada es una discapacidad".

Por consiguiente, la LGD ha llevado a cabo una definición de discapacidad como un concepto jurídico indeterminado que tiene como núcleo de certeza o centro del concepto normativo las barreras sociales por un lado y, por otro, la inexistencia de medidas de apoyo ordinarias o comunes para sortear dichos obstáculos que le impiden a la persona con algún tipo de déficit previsiblemente permanente poder tener una participación real y efectiva en la sociedad.

Es claro que estas barreras sociales la LGD quiere eliminarlas (siguiendo el art. 9 de la Convención) y a medio y largo plazo propone

el mismo precepto- "no excluirá los productos de apoyo para grupos particulares de personas con discapacidad, cuando lo necesiten". 
para ello el ya citado "diseño universal o diseño para todas las personas” pues de esta manera se conseguiría, lisa y llanamente, la plena y efectiva inclusión social del colectivo de personas con discapacidad. Pero es también cierto que hasta que ese ideal social se consiga, si es que ello es posible, esta norma entendemos que pretende también poner el foco de atención en los medios que deben articularse para sortear dichas barreras mientras éstas existan.

En fin, la discriminación para las personas con discapacidad la provoca tanto la existencia de barreras sociales como la inexistencia de medidas de apoyo de todo tipo que permitan sortear dichos obstáculos hasta que éstos se pueden eliminar. Habría, pues, dos pautas esenciales para abrogar la discriminación que provoca la discapacidad: de una parte, la eliminación de las barreras sociales a través del diseño universal o para toda persona y, de otra, el establecimiento de medidas de apoyo mientras aquellas existan para sortear sus efectos negativos para las personas con discapacidad. Ambos sistemas consiguen de manera efectiva la accesibilidad universal que, como se indica en el artículo 2.k) de la LGD "es la condición que deben cumplir los entornos, procesos, bienes, productos y servicios, así como los objetos, instrumentos, herramientas y dispositivos, para ser comprensibles, utilizables y practicables por todas las personas en condiciones de seguridad y comodidad y de la forma más autónoma y natural posible".

Las barreras u obstáculos no son sólo físicos, sino también psicológicos o sociales, igual de complejos unos y otros: la segregación educativa, la postergación en el empleo, el estigma de varios colectivos de personas con discapacidad, etc. (Moral, 201 2: 38-39). Como antes dijimos, en el concepto de persona con discapacidad utilizado en la LGD no se listan las barreras al utilizarse un concepto jurídico indeterminado que le permite adaptarse a la propia evolución de la categoría con el paso del tiempo. Por lo que respecta a las barreras sociales o actitudinales que provocan estigma o rechazo a determinados colectivos de personas con discapacidad, señaladamente el colectivo mental y también el intelectual, es posible que el diseño universal o para toda persona no sea suficiente para eliminarlas y, por ello, sea necesario que adopten un papel protagonista las medidas de apoyo que pueden ser más eficaces para la superación de aquellas, entre las que estaría la elaboración de planes de sensibilización y políticas de protección del colectivo.

Para confrontar nuestra tesis, nos podríamos fijar en la situación de personas con déficit visual que pueden superar las barreras que conlleva tal situación con unas simples gafas. Años o incluso siglos atrás, tales personas tendrían la consideración de personas con discapacidad pero hoy no porque tienen una medida de apoyo que aunque tiene un coste económico en ocasiones importante, se considera que es un artilugio corriente y habitual y, por ello, no puede considerarse que tales personas detenten una discapacidad.

Otros ejemplos podrían ser las personas con SIDA o VIH las cuales en un primer momento fueron consideradas como personas con discapacidad y así se contempló en el baremo establecido en el Real Decreto I I69/2003, de I 2 de septiembre (BOE de 4 de octubre). No obstante, años después, tras la evolución tanto de la medicina como de la concepción social, este colectivo ha podido normalizar su situación y tener, en términos generales, una inclusión social prácticamente sin merma en comparación con el resto de la sociedad, aunque en algunos casos se sigan considerando personas con discapacidad por los efectos concretos de la patología en algunas personas. ¿Qué impide considerar a una persona afectada por esta inmunodeficiencia como persona con discapacidad? La existencia de medidas de apoyo de todo tipo (pastillas farmacológicas, revisiones periódicas, posibilidad de permisos laborales para atenderlas, campañas publicitarias que han paliado en gran medida el estigma del colectivo aunque aún queda camino por recorren en este ámbito, etc.) que han conseguido prácticamente la participación plena y efectiva en igualdad de condiciones con los demás (Ministerio de Sanidad, Servicios Sociales e Igualdad, 20I6). 
Situación semejante podrían tener los afectados por problemas graves de riñón cuando les han podido realizar un trasplante de dicho órgano. Tras la operación, si no hay incompatibilidad o algún grado de repulsión por el cuerpo del nuevo riñón, es posible que su situación mejore de tal manera que no precise otras medidas de apoyo suplementarias por lo que dejaría de tener la consideración de persona con discapacidad. En otras ocasiones, aunque se haya realizado el trasplante, la persona queda mermada en su capacidad hasta tal punto que debe necesitar medidas de apoyo concretas y ajustadas a su situación, lo que le llevaría a ser considerada persona con discapacidad.

Otro colectivo que podríamos estudiar sería el de las personas intolerantes al gluten, comúnmente conocidos como celíacos. Hasta hace muy poco tiempo, tener esta condición era considerada una clara discapacidad porque le exigía unas medidas de apoyo muy concretas y extraordinariamente costosas. En el momento en que estas medidas se han ido normalizando y generalizado (<www. celiacos.org $>$ ) y en cualquier establecimiento se puede comprar los productos para la elaboración de la dieta que las personas afectadas por este déficit precisan y, además, cuando adquirirlos ya no tiene prácticamente diferencia de precio, los integrantes de este colectivo pasarán a no ser considerado como personas con discapacidad. Y ello no porque no tengan un déficit, pues siguen teniéndolo, y tampoco porque no tengan algunas barreras para su participación social (entre ellas, el mayor coste de la comida o las extremas dificultades para poder comer fuera del domicilio), sino porque $-\mathrm{y}$ este es el elemento en el que queremos incidir-, existen medidas de apoyo que se han conseguido generalizar. Esto es, la sociedad ha podido, o quizá sería mejor decir “está pudiendo ser”, cada vez más inclusiva con el colectivo de las personas celíacas.

Pensemos también en el caso muy concreto del atleta sudafricano Pistorius. Evidentemente es una persona afectada por una deficiencia física permanente importante: le faltan parte de las dos extremidades inferiores porque tuvieron que amputárselas al haber nacido sin peroné. No obstante, a pesar de ello, ha conseguido la participación plena, efectiva y en igualdad de condiciones en la sociedad como lo demuestra haber podido participar en los Juegos Olímpicos de Londres 20 I 2 y, por tanto, estar entre los mejores corredores del mundo de ese año. ¿Cómo ha podido conseguirlo? A través de unas medidas de apoyo muy concretas que le han permitido adaptar su situación y conseguir superar las barreras existentes para que una persona con esa deficiencia física pueda correr como una más con el resto de los mejores corredores de la sociedad. Entonces, ¿este atleta no tiene la consideración de persona con discapacidad? Si siguiéramos el razonamiento de que la discapacidad no es sinónimo de deficiencia y de que sólo se debe considerar persona con discapacidad a aquella cuya participación no es posible que sea plena y efectiva en la sociedad, en igualdad de condiciones del resto, parecería que el atleta Pistorius no podría ser considerado persona con discapacidad. Y ello porque existe una medida de apoyo, en este caso unas prótesis muy sofisticadas, que le ha permitido superar las barreras que le dificultaban la efectiva inclusión social. Si nos quedáramos aquí estaríamos obviando un aspecto determinante: las medidas de apoyo que esta persona precisa son extraordinarias, en el sentido más propio del término de "fuera de lo común u ordinario", para conseguir su plena igualdad de condiciones con el resto de corredores de la sociedad.

Por tanto, la discapacidad encierra desde este punto de vista dos diferentes situaciones: una, que no haya medidas de apoyo para superar las barreras que la sociedad presenta en relación a las personas con deficiencias permanentes. Y dos, también se considerará persona con discapacidad cuando, aun existiendo dichas medidas de apoyo, son tan extraordinarias y suponen una dependencia de tal calibre de la persona en relación a dichos apoyos, que sin ellos la persona no podría integrarse efectivamente en la sociedad y en igualdad de condiciones con el resto. El caso del atleta Pistorius es muy gráfico para poder identificar esta cuestión. Pero piénsese también en el caso de las gafas y otras ayudas técnicas que han permitido superar las barreras que las 
deficiencias otrora presentaban. Si el apoyo que en un momento dado es considerado fuera de lo común pasa con el devenir de la historia, el avance de la ciencia y la sensibilidad social, a ser ordinario, la persona que presenta un determinado déficit permanente y que en su momento se consideró una persona con discapacidad, puede dejar de tener esa condición porque cuenta con medidas de apoyo que le permiten su plena integración social.

Podríamos seguir estudiando con otros colectivos que están insertos dentro del gran colectivo de las personas con discapacidad pero entendemos que ya se ha puesto en evidencia que la esencia del término discapacidad es, sencillamente, junto a la existencia de barreras sociales, la falta de medidas de apoyo suficientes para sortear dichas barreras y conseguir la participación plena y efectiva en la sociedad de las personas afectadas por una deficiencia previsiblemente permanente. Por todo lo anterior, es necesario que tengan un mayor protagonismo estos apoyos en la propia noción de discapacidad. No obstante, antes de estudiar qué repercusiones prácticas tendría nuestra tesis, tenemos que estudiar la jurisprudencia del Tribunal de Justicia de la Unión Europea (en adelante, TJUE) en relación al concepto de discapacidad.

\section{El concepto de discapacidad en la jurisprudencia del TJUE}

El TJUE se ha encargado del concepto de discapacidad a la hora de aplicar e interpretar la Directiva 2000/78/CE, de 27 de noviembre, relativa al establecimiento de un marco general para la igualdad de trato en el empleo y la ocupación, por motivos de religión o convicciones, de discapacidad, de edad o de orientación sexual (en adelante, Directiva 2000/78).

Son tres las sentencias (en adelante, S o SS según esté en singular o plural) fundamentales que vamos a revisar en las que el TJUE se encarga de realizar una definición de discapacidad, a saber: SSTJUE de I I de julio de 2006 (asunto C-I3/05, Chacón Navas), de I I de abril de 2013 (asuntos acumulados C-335/I I y C-337/I I, HK Danmark) y de I 8 de marzo de 2014 (asunto C-363/I 2, Z y A). La primera de ellas fue, sin duda, muy relevante en su momento pues llegó a establecer las bases esenciales del concepto para el TJUE pero es en la segunda cuando dicho tribunal amolda su jurisprudencia a la Convención de Naciones Unidas por lo que es la que en estos momentos debe tomarse más en consideración. Por su parte, la última sentencia referida, de I 8 de marzo de 20I4, sirve para apuntalar la concepción de la discapacidad tal como la entiende actualmente el TJUE.

Recuérdese que mientras el Tratado no incluyese una disposición que pudiese facultar a las instituciones europeas a adoptar medidas obligatorias en materia de protección de derechos de las personas con discapacidad, las únicas actuaciones de la Unión en este ámbito iban a circunscribirse en el ámbito laboral dentro de la Política Social comunitaria, en el terreno conocido como "soft law" comunitario (Blázquez, 20I 2: I386). Y tal base jurídica se incorporó por primera vez en el artículo I 3 del Tratado de la Unión Europea (actual artículo I9 del Tratado de Funcionamiento de la Unión Europea tras la reforma de Lisboa), incluido por el Tratado de Ámsterdam, por el que se otorgan poderes específicos a la Unión para que actúe contra toda discriminación por motivo de sexo, de origen racial o étnico, religión o creencias, discapacidad, edad o tendencias sexuales, siendo, como se sabe, la primera vez que se inserta en los Tratados una cláusula específica sobre no discriminación entre otros motivos, por discapacidad. Recuérdese asimismo, cómo el propio Tratado de Ámsterdam reforzó la garantía establecida en el artículo I 3 a través de la declaración número 22 integrada en el Acta final por la cual se insta a las instituciones europeas a tener en cuenta las necesidades de las personas con discapacidad en la elaboración de sus políticas y medidas (Blanco, 2012: 95 y I07; Martínez, 2007: 87I). 
No obstante, no es hasta la Sentencia Chacón Navas de 2006 el momento en el que el TJUE debe analizar el concepto de discapacidad como concepto jurídico comunitario. Tal como se indica en dicha sentencia, apartado 39, el concepto de discapacidad no viene definido en la propia Directiva 2000/78 y tampoco se remite al Derecho de los Estados miembros para su definición pero, según se recoge en el apartado 40, para una aplicación uniforme del Derecho Comunitario y según se desprende del principio de igualdad, cuando una disposición de Derecho Comunitario no contiene una remisión expresa al Derecho de los Estados miembros, es preciso que sea objeto de una interpretación autónoma y uniforme en toda la Comunidad para determinar su sentido y su alcance, teniendo en cuenta el contexto de la disposición y el objetivo que la normativa de que se trate pretende alcanzar.

Tal definición en un primer momento se llevó a cabo por la sentencia Chacón Navas (apartado 43 ) indicando que "se refiere a una limitación derivada de dolencias físicas, mentales o psíquicas y que suponga un obstáculo para que la persona de que se trate participe en la vida profesional”. Al utilizar el término 'discapacidad' en el artículo I de la Directiva 2000/78 el legislador escogió deliberadamente un término que difiere del de 'enfermedad'. Por ello, el TJUE excluye la equiparación pura y simple de ambos conceptos.

Continúa el tribunal indicando en el apartado 45: "El decimosexto considerando de la Directiva 2000/78 establece que la adopción de medidas de adaptación a las necesidades de las personas con discapacidad en el lugar de trabajo desempeña un papel importante a la hora de combatir la discriminación por motivos de discapacidad. La importancia que el legislador comunitario atribuye a las medidas destinadas a adaptar el puesto de trabajo en función de la discapacidad demuestra que tuvo en mente supuestos en los que la participación en la vida profesional se ve obstaculizada durante un largo período. Por lo tanto, para que la limitación de que se trate pueda incluirse en el concepto de 'discapacidad' se requiere la probabilidad de que tal limitación sea de larga duración.”
Y, en fin, termina en este punto la STJUE Chacón Navas manteniendo que "la Directiva 2000/78 no contiene indicación alguna que sugiera que los trabajadores se encuentran protegidos en virtud de la prohibición de discriminación por motivos de discapacidad tan pronto como aparezca cualquier enfermedad".

Esta resolución ha sido calificada de 'restrictiva' y 'literal' en cuanto a su concepción de la discapacidad se refiere pues "el Tribunal evita referirse a la definición dada por la Organización Mundial de la Salud (OMS) que, de haberse acogido como propia, hubiera permitido extender la protección otorgada por la directiva a las personas con una enfermedad susceptible de producir deficiencias que pudieran discapacitar al individuo" (Blázquez, 20I 2: I396).

Unos años después de la Sentencia Chacón Navas, el TJUE vuelve a enfrentarse al concepto de discapacidad cuando ya se había promulgado la Convención de Naciones Unidas y tras la aprobación por la Unión de la citada Convención por medio de la Decisión 2010/48 que conlleva, como se indica en el apartado 30 de la sentencia HK Danmark, que sus disposiciones formen parte integrante del ordenamiento jurídico de la Unión y, por tanto, "la Directiva 2000/78 debe interpretarse, en la medida de lo posible, de conformidad con dicha Convención” (apartado 32 de la última sentencia referida).

Teniendo en cuenta lo anterior, el TJUE en su sentencia HK Danmark (apartado 38) viene a amoldar su concepto de discapacidad a la Convención de Naciones Unidas y, por ello, establece que "se refiere a una limitación, derivada en particular de dolencias físicas, mentales o psíquicas que, al interactuar con diversas barreras, puede impedir la participación plena y efectiva de la persona de que se trate en la vida profesional en igualdad de condiciones con los demás trabajadores". Y concluye (apartado 4I) que procede estimar que, si una enfermedad curable o incurable acarrea una limitación del tipo de la antes indicada en el apartado 38 , y si esta limitación es de larga 
duración, "tal enfermedad puede estar incluida en el concepto de 'discapacidad' en el sentido de la Directiva 2000/78". Por tanto, apartado 42, si una enfermedad no supone una limitación de esta índole, no estará comprendida en el concepto de discapacidad porque, en línea de lo establecido en la sentencia Chacón Navas, "la enfermedad en cuanto tal no puede considerarse un motivo que venga a añadirse a aquellos otros motivos en relación con los cuales la Directiva 2000/78 prohíbe toda discriminación".

Además de lo anterior la sentencia HK Danmark realiza otras dos afirmaciones verdaderamente importantes desde nuestro punto de vista. Por un lado, establece que "el concepto de 'discapacidad' (...) debe entenderse en el sentido de que se refiere a un obstáculo para el ejercicio de una actividad profesional, pero no (...) como una imposibilidad de ejercer tal actividad" (apartado 44). Y, por otro, estipula que "la constatación de la existencia de una discapacidad no depende de la naturaleza de los ajustes, como la utilización de equipamiento especial. A este respecto, procede señalar que la definición del concepto de 'discapacidad' en el sentido del artículo I de la Directiva 2000/78 precede a la determinación y a la apreciación de las medidas de ajuste adecuadas a que se refiere el artículo 5 de ésta" (apartado 45) y, por lo tanto, termina aseverando en el apartado 46 que estas medidas de ajuste "son la consecuencia y no el elemento constitutivo del concepto de discapacidad" y, por ello, la obligación legal de realizar estos ajustes sólo se aplica "a condición de que exista [previamente] una discapacidad".

En último término, la STJUE de I 8 de marzo de 2014 , asunto Z y A, en sus apartados 79 a 83 ratifica una cuestión ya apuntada en las sentencias anteriormente citadas cual es que la enfermedad o afección que aqueja a la persona debe provocar una limitación que le impida su participación plena y efectiva en la vida profesional en igualdad de condiciones con los demás trabajadores. En el supuesto de hecho de la sentencia que se comenta la actora sufría una incapacidad para tener hijos. Es una dolencia física que provoca una limitación cierta pero no le impide ni acceder, ni ejercer, ni progresar en un empleo. Por ello razona el TJUE que tal afección no constituye una 'discapacidad' en el sentido de la Directiva 2000/78.

De la lectura de todas estas resoluciones judiciales se pueden extraer las siguientes consideraciones:

a. Para el TJUE la nota más importante para identificar cuándo estamos en presencia de una discapacidad es la existencia de una limitación a largo plazo.

b. Que dicha limitación es causada en particular por dolencias físicas, mentales o psíquicas que, al interactuar con diversas barreras puede impedir la participación plena y efectiva de la persona en la vida profesional en igualdad de condiciones con los demás trabajadores.

c. Que no toda enfermedad debe equipararse a discapacidad ya que sólo entrará en este concepto aquélla que provoque una limitación que impida bien el acceso, bien el ejercicio, bien el progreso en un empleo, en comparación con el resto de trabajadores.

d. Que la discapacidad debe entenderse "que se refiere a un obstáculo para el ejercicio de una actividad profesional, pero no (...) como una imposibilidad de ejercer tal actividad".

e. Y, en quinto lugar, "la constatación de la existencia de una discapacidad no depende de la naturaleza de los ajustes, como la utilización de equipamiento especial”. Y, por ello, las medidas de ajuste "son la consecuencia y no el elemento constitutivo del concepto de discapacidad" de ahí que la obligación legal de realizar estos ajustes sólo se aplica "a condición de que exista [previamente] una discapacidad”.

De todas estas consideraciones que resumen la concepción de la discapacidad para el TJUE se concluye que el foco de atención está no tanto en la deficiencia o dolencia "física, mental o psíquica" (nótese que no hay sensorial y la 
psíquica se equipara a intelectual) sino en la limitación que provoca ésta al interactuar con barreras 'diversas' (no se especifican cuáles son en ningún momento). Dicha limitación debe atesorar dos características:

Por un lado, que sea de un cierto grado o, en otras palabras, relativamente importante. Cualquier limitación, enfermedad o afección no es una discapacidad. Debe impedir la participación plena y efectiva en la sociedad en general y en la vida profesional en particular.

Por otro, que sea una limitación "a largo plazo", aunque no requiere que sea ni permanente y puede ser curable.

A diferencia de lo que nosotros mantenemos, el TJUE sostiene que la noción de discapacidad es independiente de las medidas de ajuste que se puede articular para paliarla. Primero se determina que existe una discapacidad, eso es, una limitación y a partir de aquí ello conlleva la obligación legal de articular medidas de apoyo o ajustes razonables pues el TJUE -se reiteran sus propias palabras-, entiende que las medidas de ajuste "son la consecuencia y no el elemento constitutivo del concepto de discapacidad" (apartado 46, sentencia de I I de abril de 20I3, HK Danmark, asuntos acumulados C-335/I I y C-337/II).

5. La necesidad de un mayor protagonismo de los apoyos en la propia noción de discapacidad

Tras analizar la definición legal de discapacidad llevada a cabo por la LGD y la jurisprudencia del TJUE podríamos resumir didácticamente el concepto de discapacidad, con las cuatro ideas siguientes:

I. Diferencia específica de las personas a las que afecta.

2. De origen personal (deficiencia) y, sobre todo, social (barreras).
3. Que genera desigualdad social objetiva para participar en la vida política, económica, cultural y social y, en concreto, en el ámbito laboral, provoca una limitación que impide bien el acceso, bien el ejercicio, bien el progreso en un empleo, en comparación con el resto de trabajadores. La Convención indica en su letra 'y' del Preámbulo que provoca una "profunda desventaja social” y la Exposición de Motivos de la ya derogada LIONDAU lo expresa indicando que son "personas que tienen especiales dificultades para satisfacer unas necesidades que son normales".

4. Que es provocada tanto por la existencia de barreras como por la falta de medidas de apoyo para poder sortear dichas barreras sociales existentes.

De estas cuatro notas, la última de ellas aún no está suficientemente recogida en el Ordenamiento Jurídico. Es cierto que la propia Convención en la letra j) del Preámbulo ${ }^{3}$, in fine, da a entender que todas las personas con discapacidad necesitan apoyo y algunas en concreto en mayor medida, pero esta idea no se ha trasladado a la definición del colectivo ni en la norma internacional, ni en la LGD y, como consecuencia de ello, el TJUE mantiene que las medidas de ajuste "son la consecuencia y no el elemento constitutivo del concepto de discapacidad" (apartado 46, sentencia de I I de abril de 20I3, HK Danmark).

Desde nuestro punto de vista la cuestión no es, para nada, baladí, ya que de lo que estamos hablando es que en el mismo concepto neurálgico de discapacidad esté la nota de

3. Literalmente, reza, “j) Reconociendo la necesidad de promover y proteger los derechos humanos de todas las personas con Discapacidad, incluidas aquellas que necesitan un apoyo más intenso" [el subrayado es nuestro]. Por su parte, el artículo 8.2 de la LIONDAU recogía esta idea al indicar que hay ciertas personas con Discapacidad que precisan medidas de acción suplementarias porque "objetivamente sufren un mayor grado de discriminación o presentan menor igualdad de oportunidades" y, en alguna medida, se ha trasladado al artículo 7.4 de la LGD aunque ya no habla de apoyos suplementarios sino de "personas o grupos de personas especialmente vulnerables a la discriminación múltiple” razón por la cual "las administraciones públicas protegerán de manera singularmente intensa". 
que es provocada por la carencia de unas medidas de apoyo específicas y de muy diversa índole. Si se consiguiera que con el "diseño universal o diseño para todas las personas” antes ya mencionado, la sociedad en general pueda ser accesible, en el sentido recogido en el artículo 2. k) LGD de que todo pueda ser "utilizable y practicable por todas las personas en condiciones de seguridad y comodidad y de la forma más autónoma y natural posible”, quizá no hiciera falta poner tanto énfasis como nosotros mantenemos en las medidas de apoyo que las personas con discapacidad necesitan. Pero hasta ese momento entendemos que, si se sigue nuestro criterio, más importante que la deficiencia que presenta la persona con discapacidad es el apoyo que puede suplir las barreras sociales y, en general, el problema (la limitación en palabras del TJUE) que conlleva aquella. Y ello llevaría a poner el foco, no tanto en lo que no puede o le cuesta hacer a la persona con discapacidad sino en la estructura de apoyo que debemos articular entre todos. Por consiguiente, en el Derecho de la Discapacidad, más importancia deberían empezar a tener los apoyos que necesita la persona, que las carencias o limitaciones que presente.

Ya se ha dado un paso en el art. I2.3 a) de la LGD en el cual se recoge que los equipos multiprofesionales de calificación y reconocimiento del grado de discapacidad deben emitir un dictamen técnico "sobre las deficiencias, las limitaciones para realizar actividades y las barreras en la participación social, recogiendo las capacidades y habilidades para las que la persona necesita apoyos" (la cursiva es nuestra). Esto es, ya no sólo se identifican las deficiencias y las limitaciones que éstas provocan sino también las barreras que provocan tales limitaciones y las capacidades y habilidades que atesora la persona. Pero aún falta identificar qué apoyos concretos precisa la persona. Este es desde nuestro punto de vista el gran reto para los próximos años.

Ciertamente, si uno lee tanto la Convención como la LGD que refunde como ya se ha dicho las anteriores LISMI y LIONDAU, son múltiples las referencias a la necesidad de que existan los apoyos que precisa la persona con discapacidad. En especial, el artículo 57.I LGD establece como una obligación que "los poderes públicos garantizarán (...) los apoyos adecuados" ${ }^{4}$, dicción que modifica lo establecido en el art. 3.I de la ya derogada LISMI que hablaba de "rehabilitación adecuada", poniendo de relieve la importancia que tienen los apoyos en el Derecho de la Discapacidad. También en el Derecho de la Unión Europea en la antes citada Directiva 2000/78/CE, se habla en reiteradas ocasiones sobre las medidas de apoyo o bien los ajustes razonables. En concreto, en la Convención hay dieciocho menciones a los apoyos y en la LGD este número se dobla para llegar hasta en treinta y seis ocasiones a nombrar los diferentes apoyos que precisan las personas con discapacidad. Por su parte, en la Directiva de la UE antes citada hay seis referencias expresas a este tema. Y todo ello en la línea de lo indicado en la Exposición de Motivos de la LGD en la cual se llega a decir que "el amparo especial y las medidas de equiparación para garantizar los derechos de las personas con discapacidad [deben] basarse en apoyos complementarios, ayudas técnicas y servicios especializados, que les [permitan] llevar una vida normal en su entorno". Por ello, la importancia de los apoyos para el colectivo de personas con discapacidad queda más que evidenciada, pero no se entiende cómo no se ha instalado aún en la propia definición de persona con discapacidad que hace la Convención y, por ende, nuestra LGD.

La conclusión es clara desde la posición que mantenemos, en la discapacidad nos seguimos fijando más en la deficiencia, en la carencia, que en los apoyos, en los baluartes que la sociedad pone a disposición de las personas con discapacidad para conseguir no sólo su participación efectiva y la igualdad de oportunidades real sino, más aún, evitar, ex ante, que pueda existir siquiera la discapacidad. Así ha sido toda la historia y en el propio

4. En este precepto se recoge además la obligación de garantizar "la prevención, los cuidados médicos y psicológicos, los apoyos adecuados, la educación, la orientación, la inclusión social y laboral, el acceso a la cultura y al ocio, la garantía de unos derechos económicos, sociales y de protección jurídica mínimos y la Seguridad Social”. 
término ha tenido su reflejo. Siempre se ha puesto el énfasis en la no-capacidad (discapacidad), el menor-valor (minusvalía), el ser disminuido como todavía reza el artículo 49 de nuestra Constitución, ser impedido, subdotado o deficiente en la terminología de mediados del siglo pasado, etc. Con nuestra concepción, la persona con discapacidad lo es por la falta de los apoyos necesarios. Por tanto, insistimos para resumir, en el propio término de discapacidad debería tener un mayor peso que es provocada por la falta de un bastión articulado socialmente que permita a la persona con deficiencia previsiblemente permanente sortear las barreras sociales existentes, mientras éstas sigan existiendo.

La trascendencia práctica de esta visión es evidente: más importante que el reconocimiento del grado de discapacidad en sí serán los apoyos y medidas concretas que éste conlleva. De nada sirve que se declare una discapacidad sin que conjuntamente con ello se establezca el andamiaje que se le ofrece a la persona para sobrellevarla. Así se procede en la esfera de la Ley 39/2006, de Promoción de la Autonomía Personal y Atención a las Personas en Situación de Dependencia y así debería realizarse en la órbita de la discapacidad.

De esta manera, y dado que "la discapacidad es un concepto que evoluciona”, como indica la Convención en la letra e) de su Preámbulo (ya puesto de manifiesto por Esteban, I999: 45), el seguimiento de los apoyos y su actualización permanente es una cuestión central, pues si están bien diseñados y ejecutados, con seguridad necesitarán ser revisados con frecuencia para adaptarse a la nueva situación que necesite la persona con discapacidad e incluso podrán conseguir que la discapacidad ya no sea tal porque el apoyo es ordinario y frecuente y ya impide considerar a la persona con una determinada deficiencia que cuenta con apoyos suficientes para su inserción social plena como tal persona con discapacidad.

\section{El contenido de los apoyos para superar las barreras sociales mientras éstas subsistan}

Siendo el objetivo social principal la extirpación de las barreras existentes para con las personas con discapacidad (art. 9 de la Convención) hasta que no se consiga es esencial contar con una batería de apoyos para sortear dichas barreras sociales. En el estudio del contenido de estos apoyos debemos partir de un análisis somero del concepto de aquellas, esto es, "los obstáculos que impiden el desarrollo personal, la libre elección y el pleno disfrute de la vida social y en comunidad". De este modo, se distinguen entre barreras legales, sociales, incluyendo aquí las económicas, físicas y de comunicación cuyo efecto es que provocan que todos los productos, los servicios y los entornos no puedan ser disfrutados o se beneficien de ellos todas las personas (CERMI, 20I6: 4-6). Como antes dijimos, el diseño universal trata de construir de inicio un entorno, productos y servicios que sí tengan en cuenta las diferentes capacidades de las personas.

Teniendo en cuenta lo anterior, el contenido de los apoyos debe ser lo más amplio posible pues lo cierto es que se precisa la adopción de medidas de todo tipo que tengan como finalidad revertir esta situación y conseguir la igualdad de las personas con discapacidad. Nos situamos pues en el ámbito del artículo 9.2 de nuestra Constitución española que recoge un mandato a los poderes públicos para que remuevan todos los obstáculos necesarios para conseguir la igualdad real y efectiva entre los ciudadanos. En palabras de nuestro Tribunal Constitucional en una sentencia de sus primeros años, el artículo 9.2 CE "contiene un mandato a los poderes públicos para que promuevan las condiciones para que la libertad e igualdad del individuo y de los grupos en que se integran sean reales y efectivos, y para que remueva los obstáculos que impidan o dificulten su plenitud, puede actuar como un principio matizador de la igualdad formal consagrada en el art. I4 de la Constitución” (STC 98/198 5, F. J. 9 in 
fine). Tal precepto, pues, verdadero exponente de la proclamación constitucional del Estado Social de Derecho del primer artículo de nuestra Carta Magna (Martínez-Pujalte, I997: 85), resulta ser, como nos recuerda Giménez Glück, una opción política que propicia un ámbito de tutela cuyo objetivo no es otro que abolir las desigualdades materiales entre personas y colectivos, pudiéndose dispensar además "un trato formalmente desigual a favor de los desfavorecidos” (Giménez, 2008: 39).

Por tanto, la noción de apoyos necesarios sería un concepto que englobaría la accesibilidad, los ajustes razonables y aquellas otras medidas de sensibilización o de promoción del colectivo que fueran necesarias para la igualdad real y efectiva de las personas con discapacidad. Es decir, se entenderían dentro de los apoyos necesarios para las personas con discapacidad los siguientes:

a. La accesibilidad (artículo 2.k de la LGD) que, como se sabe, "implica pensar y crear los entornos, productos, servicios y transportes para que puedan ser utilizables por todos en condiciones de seguridad y máxima autonomía". Se trata de un concepto vivo que supone no desatender "las cadenas de accesibilidad" pues ésta es una cadena de elementos interrelacionados, de forma que si falla uno, falla la accesibilidad completa (CERMI, 20I 6: 9-IO).

b. Los ajustes razonables: aquellos que pretenden transformar el entorno para hacerlo corresponder con las necesidades específicas de las personas con discapacidad, en todas las situaciones concretas en que éstas puedan hallarse y proporcionarles una solución (Pérez Bueno, 2012: I96). Serían "respuestas a medida" que complementan la accesibilidad y/o el diseño universal (CERMI, 20I6: I I). Su regulación jurídica está situada en el artículo 2 de la Convención y 2m, 63 y 66 de nuestra LGD.

c. Otras medidas necesarias como planes de sensibilización, campañas antiestigma, medidas de acción positiva y de discriminación inversa, etc. Las medidas de acción positiva consisten en desarrollar actuaciones públicas que no perjudican a nadie pero que promocionan al colectivo de personas con discapacidad (reguladas en el artículo 2.g, 67 y 68 de la LGD.

Ejemplos podrían ser las ayudas económicas y subvenciones que promocionan la contratación de personas con discapacidad o las desgravaciones fiscales existentes). Por su parte, las de discriminación inversa (reguladas en los artículos 67 y 68 de la LGD y 17.2, 3 y 4 del Estatuto de los Trabajadores), son medidas en las que sí hay o potencialmente puede haber personas que puedan salir perjudicadas, como la cuota de reserva o la elección de una persona con discapacidad en detrimento de otra persona sin dificultad de inclusión laboral.

Como se observa, el género sería las medidas de apoyo, y especies de éstas serían la accesibilidad, los ajustes razonables, las medidas de acción positiva y de discriminación inversa, etc. Tales medidas de apoyo irían mutando con el tiempo para lograr la equiparación real y efectiva de las personas con discapacidad. Exponer con detalle cada una de estas figuras excedería los límites del presente trabajo pero debemos remarcar cómo estos apoyos necesarios abarcarían desde medidas de carácter general a aquellas medidas específicas para casos particulares. Todas son obligación de los poderes públicos. Las de carácter general serían reivindicadas por grupos políticos, sindicatos o por el movimiento asociativo de la discapacidad. Y en relación a las de carácter particular la virtualidad práctica de este concepto sería lograr que cada persona con discapacidad en el momento de ser declarada como tal pueda tener un documento en el que se relacionen las medidas de apoyo que precisa de manera específica y personalizada y que puedan ser un auténtico derecho para la persona y un deber para los poderes públicos. Y que tales medidas evolucionen y se adapten a las circunstancias cambiantes de cada persona con discapacidad. 


\section{La consideración de persona con discapacidad}

Otro tema a revisar es el regulado en el artículo 4 de la LGD que bajo el título "Titulares de los derechos" se encarga de definir quiénes son considerados en nuestro ordenamiento jurídico personas con discapacidad. Dicho precepto parte de un concepto general en su primer apartado que considera persona con discapacidad con independencia de tener un reconocimiento previo administrativo oficial. Pero, a continuación, en el apartado segundo la LGD identifica que "además” tendrán la consideración de persona con discapacidad "a todos los efectos" quienes tengan "reconocido un grado de discapacidad igual o superior al 33 por ciento". Tal reconocimiento del grado de discapacidad como indica el apartado tercero “deberá ser efectuado por el órgano [administrativo] competente en los términos desarrollados reglamentariamente".

Por tanto, como se observa, para la LGD una persona puede tener la consideración jurídica de persona con discapacidad con independencia de tener previamente reconocida esta condición administrativamente. Para ello, basta con que la persona demuestre que presenta una deficiencia física, mental, intelectual o sensorial, previsiblemente permanente que le impide una participación plena y efectiva en la sociedad, en igualdad de condiciones que los demás, por existir barreras sociales, para que sea considerada persona con discapacidad.

Nuestra LGD se alinea, como no podía ser de otra manera, con la Convención en una concepción garantista de discapacidad que no exige un reconocimiento administrativo previo para que tal condición pueda tener efectos jurídicos de protección para la persona.

Así, además, fue interpretado por el TJUE, como antes tuvimos ocasión de estudiar, en su Sentencia de I I de abril de 20I3, Danmark, antes citada, en cuyo apartado 47 indica que existe discapacidad cuando existe una enfermedad, curable o no, que provoca limitaciones de larga duración, que pueden impedir la participación plena y efectiva de la persona en la vida profesional en igualdad de condiciones con los demás trabajadores. Por tanto, el TJUE no exige, como tampoco lo hace la Convención, un reconocimiento administrativo oficial previo.

Es cierto que si uno detenta tal reconocimiento oficial del grado de discapacidad, la protección lo es "a todos los efectos" como indica el artículo 4.2 LGD, pero no lo es menos que el respaldo jurídico lo tendrá toda persona que se encuentre inserta en la situación descrita en el apartado I del art. 4 LGD.

Como consecuencia de lo anterior, el artículo 64.2 LGD, precepto que refunde el art. 2.I de la LIONDAU, establece que las garantías del derecho a la igualdad de oportunidades las tendrán las personas con discapacidad "con independencia de reconocimiento oficial de la situación de discapacidad o de su transitoriedad".

Esta cuestión supone un cambio con relación a la legislación previa a la LGD pues ahora se extienden todas las medidas que promueven la plena igualdad (tanto formal como material) a toda persona con discapacidad, mientras que con anterioridad se hacía una diferenciación entre las medidas de defensa, arbitraje y carácter judicial -a las que podía acceder toda persona con independencia del grado de discapacidad que tuviera reconocido- y el resto de medidas orientadas a la igualdad de oportunidades y a la igualdad de resultados, que únicamente podían ser disfrutadas por las personas con discapacidad con reconocimiento administrativo oficial de grado igual o superior al $33 \%$. De tal cambio había llamado la atención algún autor (Sastre, 20I 2: 9I) porque había sido requerido por el Comité sobre los Derechos de las personas con discapacidad de Naciones Unidas en el informe de septiembre de 20 II.

Sin perjuicio de lo anterior, es conveniente indicar que la protección para la igualdad y no discriminación es para todas las personas 
con discapacidad pero que, para otras medidas de acción positiva o de discriminación inversa sí puede requerirse bien la declaración administrativa del reconocimiento del grado de discapacidad, bien una tipología de discapacidad y/o porcentaje, como así ocurre por ejemplo, en las medidas de incentivación y fomento del empleo reguladas en la Ley 43/2006, de 29 de diciembre, para la mejora del crecimiento y del empleo.

Adicionalmente a todo lo anterior, la LGD indica otros dos colectivos que se considera que tienen una discapacidad. Por un lado, el artículo 4.4 establece que se asimilará a la situación de persona con discapacidad a quienes se encuentren en los "estados previos, entendidos como procesos en evolución que puedan llegar a ocasionar una limitación en la actividad" y en concreto, "a efectos del reconocimiento del derecho a los servicios de prevención de deficiencias y de intensificación de discapacidades". Por otro, en el segundo inciso del artículo 4.2 indica que "se considerará que presentan una discapacidad en grado igual o superior al 33 por ciento los pensionistas de la Seguridad Social que tengan reconocida una pensión de incapacidad permanente en el grado de total, absoluta o gran invalidez, y a los pensionistas de clases pasivas que tengan reconocida una pensión de jubilación o de retiro por incapacidad permanente para el servicio o inutilidad". Tal consideración, por su interés, merece ser tratada en punto aparte.

8. Discapacidad e incapacidad, dos conceptos confundidos históricamente que ahora la ley identifica parcialmente

Para terminar de revisar el concepto jurídico de persona con discapacidad, analizaremos cómo la discapacidad y la incapacidad no son términos sinónimos. Son conceptos cercanos en los que históricamente no ha faltado la confusión (Fargas, 2002: 268). Baste recordar la polémica jurisprudencial suscitada por el ya derogado artículo I.2 LIONDAU sobre la consideración de persona con discapacidad de los pensionistas de la Seguridad Social que tuvieran reconocida una incapacidad permanente y cómo tuvo que ser solventada por la jurisprudencia de unificación de doctrina del Tribunal Supremo, cuya postura ahora ha sido ratificada por la LGD en el segundo inciso del artículo 4.2 LGD antes visto (Tuset, 20I I: 75).

Como es sabido, la separación conceptual entre la discapacidad y la incapacidad se cimenta básicamente en dos premisas: por un lado, en que la incapacidad, por definición (Alonso y Tortuero, I998: 95 y 269; Álvarez, I982), es sobrevenida: presupone la imposibilidad de volver a llevar a cabo (total o parcialmente) algo que antes sí se podía realizar; mientras que, por su parte, la discapacidad puede ser como declaraba el artículo 7 de la ya derogada LISMI "de carácter congénito o no" (por cierto, que tal extremo no se ha incorporado en la refundición llevada a cabo por la LGD). Por otro y más importante a estos efectos, la incapacidad se circunscribe al ámbito del trabajo (Alonso y Tortuero, I998: 269), qué limitación ha originado en su capacidad profesional (Álvarez, I982: 21 5) y la discapacidad provoca restricciones no sólo en el plano laboral sino también en el educativo, económico y, en general, en su participación social (Alonso-Olea, 2009: 56).

Nos fijaremos ahora en la primera nota de diferenciación pues, como hemos dicho, mientras la incapacidad consiste en que cuando deviene ésta, no se puede hacer -o no del mismo modo- una actividad que antes sí se podía ejecutar, la discapacidad presupone no la imposibilidad total sino la existencia de barreras que lo dificultan pero que son sorteables con las medidas de apoyo precisas. En este mismo sentido, ya hicimos referencia a la postura del Tribunal de Justicia de la Unión Europea en su Sentencia de I I de abril de 2013, Danmark, que en su apartado 44 establece: "procede considerar que el concepto de 'discapacidad', tal como resulta del apartado 38 de la presente sentencia, debe entenderse en el sentido de que se refiere a un obstáculo para el ejercicio de una 
actividad profesional, pero no, como aducen DAB y ProDisplay [empresas de los litigios acumulados], como una imposibilidad de ejercer tal actividad”. Y como todo obstáculo, puede contar con algún artilugio, producto de apoyo o medida que consiga sortearlo. Por tanto, si como nosotros mantenemos en el Derecho de la discapacidad se empieza a poner mayor énfasis en las medidas de apoyo concretas que hay que procurar a cada situación que afecta a cada persona con discapacidad, las diferencias entre los conceptos de discapacidad e incapacidad podrán ser más evidentes.

Pero no es esa la postura que últimamente ha presidido las decisiones de nuestro legislador al equiparar a las personas con discapacidad y las personas que tengan reconocida una pensión de incapacidad permanente en el grado de total, absoluta o gran invalidez, incluidos también los pensionistas de clases pasivas o de retiro. En efecto, como se ha visto la LGD identifica a todos los efectos a tales personas ("Se considerará que presentan una discapacidad en grado igual o superior al 33 por ciento...”). Es por lo que decíamos antes que estos dos conceptos que otrora fueron mezclados, ahora el legislador los ha identificado siquiera parcialmente. No obstante, bajo nuestro punto de vista la cuestión es más o menos clara con las incapacidades permanentes absolutas (IPA), y por ello, creemos que efectivamente toda persona afecta de una IPA debe tener la consideración de persona con discapacidad pero dudamos que toda persona a la que se le haya declarado una incapacidad permanente en grado de total cumpla con la propia definición del artículo 4.I LGD, a saber: sea una persona afecta de una deficiencia de tipo física, mental, intelectual o sensorial previsiblemente permanente que le provoca una limitación o le impide participar plena y efectivamente en la sociedad debido a las barreras sociales existentes. Pensemos, por ejemplo, en el caso de un pianista que por infortunio pierde unas falanges de un dedo. Incluso aunque no sea la mano dominante lo más probable es que le sea declarada una Incapacidad Permanente en grado de total (IPT) porque la lesión le provoca que no pueda volver a realizar su profesión habitual. Pero, ¿de verdad que esta persona debe ser considerada como una persona con discapacidad? Quizá sea la excepción que cumple la regla pero nos tememos que no tiene por qué ser así y que sea sólo un botón de muestra de una realidad que puede ser incluso hasta frecuente (peluquera con problemas graves y permanentes para cortar con tijeras, cocinero que desarrolla una hipersensibilidad a ciertos productos que se utilizan en la cocina, pintores o limpiadores en la misma situación, encofradores con vértigos, etc.). Nuestra opinión, por tanto, está en la línea de repensarse la identificación directa entre IPT y persona con discapacidad mientras que mantendríamos las de IPA y Gran Invalidez. 
Referencias bibliográficas

Alonso, M. y Tortuero, J. L. (1998): Instituciones de Seguridad Social, Madrid: Civitas.

Alonso-Olea, B. (2009): "Capítulo segundo", en Alonso-Olea García, B. et al.: La protección de las personas con discapacidad y en situación de dependencia en el Derecho de la Seguridad Social y en el Derecho Tributario. Navarra: Editorial Aranzadi-Thomson Reuters.

Álvarez, J. M. (I982): Invalidez Permanente y Seguridad Social, Madrid: Editorial Civitas.

Blanco, E. (20I2): "El marco jurídico de la no discriminación de las personas con discapacidad en la Unión Europea”, en Pérez Bueno, L. C. (dir.) y Álvarez Ramírez, G. (coord.): 2003-2012: 10 años de legislación sobre no discriminación de personas con discapacidad en España. Estudios en homenaje a Miguel Ángel Cabra de Luna. Madrid: Ediciones Cinca.

Blázquez, M. D. (20I2): "No discriminación en razón de la discapacidad: la jurisprudencia del Tribunal de Justicia a la luz de la Directiva $2000 / 78$, relativa al establecimiento de un marco general para la igualdad de trato en el empleo y la ocupación", en Cardona Llorens, J. et al. (eds.) y Aznar Gómez, M. J. (coord.): Estudios de Derecho Internacional y Derecho Europeo en homenaje al profesor Manuel Pérez González. Valencia: Editorial Tirant lo Blanch.

Cabra de Luna, M. A. (20I4): Informe sobre contenidos más novedosos del Real Decreto Legislativo I/2013, de 29 de noviembre, por el que se aprueba el Texto Refundido de la Ley General de derechos de las personas con discapacidad y de su inclusión social (en línea). <http://semanal.cermi.es/noticia/Informecontenidos-texto-refundido-discapacidad. aspx>, acceso 3 I de enero de 2016.

CERMI (2016): Activando la accesibilidad universal. Guía Práctica 2016 (en línea). $<$ http://www.cermi.es/es-ES/Biblioteca/ Lists/Publicaciones/Attachments/378/ GU\% $3 \% 8$ DA \% 20ACCESIBILIDAD\% 202 . pdf $>$, acceso 3 I de enero de 2016.
De Asís, R. et al. (2007): "Principios éticos y fundamentos jurídicos”, en De Lorenzo, R. y Pérez Bueno, L. C. (dirs.): Tratado sobre Discapacidad. Navarra: Editorial ThomsonAranzadi.

De Asís, R. et al. (2007): "Derecho a la igualdad y a la diferencia: Análisis de los principios de no discriminación, diversidad y acción positiva", en De Lorenzo, R. y Pérez Bueno, L. C. (dirs.): Tratado sobre Discapacidad. Navarra: Editorial Thomson-Aranzadi.

De Lorenzo, R. y Cabra de Luna, M. A. (2007): "El empleo de las personas con discapacidad", en De Lorenzo, R. y Pérez Bueno, L. C. (dirs.): Tratado sobre Discapacidad. Navarra: Editorial Thomson-Aranzadi.

De Lorenzo, R. y Palacios, A. (2007): "Discapacidad, derechos fundamentales y protección constitucional”, en Laorden, J. (dir.) y Terreros, J. L. (coord.): Los derechos de las personas con discapacidad, Vol. I Aspectos jurídicos. Madrid: Consejo General del Poder Judicial.

De Lorenzo, R. y Pérez Bueno, L. C. (dirs.) (2007): Tratado sobre Discapacidad, Navarra: Editorial Thomson-Aranzadi.

España. Real Decreto Legislativo 2/201 5, de 23 de octubre, por el que se aprueba el texto refundido de la Ley del Estatuto de los Trabajadores, Boletín Oficial del Estado, 24 de octubre de 2015 .

España. Real Decreto-Legislativo I/2013, de 29 de noviembre, por el que se aprueba el Texto Refundido de la Ley General de derechos de las personas con discapacidad y de su inclusión social, Boletín Oficial del Estado, 3 de diciembre de 20I3, núm. 289, pp. $95635^{-}$ 95673 .

España. Ley 49/2007, de 26 de diciembre, por la que se establece el régimen de infracciones y sanciones en materia de igualdad de oportunidades, no discriminación y 
accesibilidad universal de las personas con discapacidad, Boletín Oficial del Estado, 27 de diciembre de 2007 , núm. 3 Io, pp. 53278 53284 .

España. Ley 43/2006, de 29 de diciembre, para la mejora del crecimiento y del empleo, Boletín Oficial del Estado, 30 de diciembre de 2006, núm. 3 I 2.

España. Ley 39/2006, de I4 de diciembre, de Promoción de la Autonomía Personal y Atención a las personas en situación de dependencia, Boletín Oficial del Estado, I 5 de diciembre de 2006, núm. 299, pp. 44I4244 I 56.

España. Ley $5 \mathrm{I} / 2003$, de 2 de diciembre, de igualdad de oportunidades, no discriminación y accesibilidad universal de las personas con discapacidad, Boletín Oficial del Estado, 3 de diciembre de 2003, núm. 289, pp. 4318743195 .

España. Real Decreto I I69/2003, de I 2 de septiembre, por el que se modifica el anexo I del Real Decreto I97I/I999, de 23 de diciembre, de procedimiento para el reconocimiento, declaración y calificación del grado de minusvalía, Boletín Oficial del Estado, 4 de octubre de 2003, núm. 238, pp. 3613636138 .

España. Ley I3/I982, de 7 de abril de integración social de [las personas con discapacidad], Boletín Oficial del Estado, 30 de abril de I982, núm. I03, pp. IIIO6-IIII2.

Esteban, R. (I999): Contrato de trabajo y Discapacidad, Madrid: Ibídem Ediciones.

Fargas, J. (2002): Análisis crítico del Sistema español de Pensiones no contributivas, Navarra: Editorial Aranzadi.

García, J. C. (2005): "El concepto jurídico laboral de discapacitado", en Valdés Dal-Ré (dir.) y Lahera Forteza, J. (coord.): Las relaciones laborales de las personas con discapacidad. Madrid: Editorial Biblioteca Nueva.

García Garnica, P. (20I I): “Capítulo primero”, en García Garnica, P. (dir.): Estudios sobre dependencia y discapacidad. Navarra: Editorial Aranzadi-Thomson Reuters.
Giménez, D. (2008): "Estado social y acciones positivas: especial consideración de las personas mayores y de las personas con Discapacidad", en Díaz Palarea, M. D. y Santana Vega, D. M. (coords.): Marco jurídico y social de las personas mayores y de las personas con discapacidad. Madrid: Editorial Reus.

Instituto de Peritaje Forense (2OI2): Baremo grado de discapacidad para enfermos VIH (en línea). <http://medicina-trabajo.blogspot.com. es/20I 2/03/baremo-grado-discapacidad-paraenfermos.html>, acceso 3 I de enero de 2016 .

Jiménez Lara, C. (2007): “Conceptos y tipologías de la discapacidad. Documentos y normativas de clasificación más relevantes”, en De Lorenzo, R. y Pérez Bueno, L. C. (dirs.): Tratado sobre Discapacidad. Navarra: Editorial Thomson-Aranzadi.

Martínez, A. (2007): “Tratamiento de la discapacidad en el Tribunal Europeo de Justicia”, en De Lorenzo, R. y Pérez Bueno, L. C. (dirs.): Tratado sobre Discapacidad. Navarra: Editorial Thomson-Aranzadi.

Martínez-Pujalte, A. L. (I997): La garantía del contenido esencial de los derechos fundamentales. Madrid: Centro de Estudios Constitucionales.

Ministerio de Sanidad, Servicios Sociales e Igualdad (20I6): Igualdad de trato y no discriminación (en línea). <http://www.msssi.gob.es/ ciudadanos/enfLesiones/enfTransmisibles/sida/ estigma.htm>, acceso 26 de mayo de 2016 .

Moral, O. (2012): "Las situaciones de discriminación de personas con discapacidad en España: vulneraciones más extendidas”, en Pérez Bueno, L. C. (dir.): y Álvarez Ramírez, G. (coord.): 2003-20 I2: Io años de legislación sobre no discriminación de personas con discapacidad en España. Estudios en homenaje a Miguel Ángel Cabra de Luna. Madrid: Ediciones Cinca.

Organización de Naciones Unidas. Convención de Naciones Unidas sobre los Derechos de las Personas con discapacidad de $\mathrm{I} 3$ de diciembre de 2006 , Resolución publicada el 24 de enero de 2007. Ratificada por España por medio de 
Instrumento de ratificación, Boletín Oficial del Estado, 2 I de abril de 2008, núm. 96, pp. 20648-20659.

Pérez Bueno, L. C. (2012): “La configuración jurídica de los ajustes razonables”, en Pérez Bueno, L. C. (dir.) y Álvarez Ramírez, G. (coord.): 2003-20I 2: Io años de legislación sobre no discriminación de personas con discapacidad en España. Estudios en homenaje a Miguel Ángel Cabra de Luna. Madrid: Ediciones Cinca.

Pérez Bueno, L. C. y De Lorenzo, R. (2007): “Los difusos límites de la discapacidad en el futuro. Hacia un nuevo estatuto de la discapacidad", en De Lorenzo, R. y Pérez Bueno, L. C. (dirs.): Tratado sobre Discapacidad. Navarra: Editorial Thomson-Aranzadi.

Sastre, A. (20I2): "La no discriminación de las personas con discapacidad en la Convención Internacional sobre los derechos de las personas con discapacidad”, en Pérez Bueno, L. C. (dir.) y Álvarez Ramírez, G. (coord.): 2003-20I2: Io años de legislación sobre no discriminación de personas con discapacidad. Estudios en homenaje a Miguel Ángel Cabra de Luna. Madrid: Ediciones Cinca.

Tuset, P. (20I I): Cincuenta cuestiones básicas en materia de personas con discapacidad. Madrid: Editorial Grupo Difusión.

Tuset, P. (2000): La contratación de trabajadores minusválidos. Pamplona: Editorial Aranzadi.

Unión Europea. Directiva 2000/78/CE, del Consejo, de 27 de noviembre de 2000 , relativa al establecimiento de un marco general para la igualdad de trato en el empleo y la ocupación. Diario Oficial de la Unión Europea $\mathrm{L}_{3} \mathrm{O}_{3}, 2$ de diciembre de 2000, pp. I6-22.

Unión Europea. Versión Consolidada del Tratado de Funcionamiento de la Unión Europea. Diario Oficial de la Unión Europea C83, 30 de marzo de 2010, pp. 47-I99. 